\title{
Large-Scale Protein Arrays Generated with Interferometric Lithography for Spatial Control of Cell-Material Interactions
}

\author{
Elizabeth L. Hedberg-Dirk and Ulises A. Martinez \\ Department of Chemical and Nuclear Engineering, Center for Biomedical Engineering, The University of New Mexico, \\ Albuquerque, NM, USA
}

Correspondence should be addressed to Elizabeth L. Hedberg-Dirk, edirk@unm.edu

Received 23 December 2009; Revised 9 May 2010; Accepted 15 May 2010

Academic Editor: Do Kim

Copyright ( 2010 E. L. Hedberg-Dirk and U. A. Martinez. This is an open access article distributed under the Creative Commons Attribution License, which permits unrestricted use, distribution, and reproduction in any medium, provided the original work is properly cited.

\begin{abstract}
Understanding cellular interactions with material surfaces at the micro- and nanometer scale is essential for the development of the next generation of biomaterials. Several techniques have been used to create micro- and nanopatterned surfaces as a means of studying cellular interactions with a surface. Herein, we report the novel use of interference lithography to create a large $\left(4 \mathrm{~cm}^{2}\right)$ array of $33 \mathrm{~nm}$ deep channels in a gold surface, to expose an antireflective coating on a silicon wafer at the bottom of the gold channels. The fabricated pores had a diameter of 140-350 nm separated by an average pitch of 304-750 nm, depending on the fabrication conditions. The gold surface was treated with 2-(2-(2-(11-mercaptoundecyloxy)ethoxy)ethoxy)ethanol to create protein-resistant areas. Fibronectin was selectively adsorbed onto the exposed antireflective coating creating nanometer-scale cell adhesive domains. A murine osteoblast cell line (MC3T3-E1) was seeded onto the surfaces and was shown to attach to the fibronectin domains and spread across the material surface.
\end{abstract}

\section{Introduction}

Cellular adhesion is an important process in many biological phenomena such as embryonic development, homeostasis, and pathogenesis. Although cells have micrometer dimensions, in vivo they are in close contact with the extracellular matrix (ECM), a substratum with topographical and chemical features of nanometer sizes [1]. Advances in material science and imaging technologies have led to the understanding that individual cell-material interactions begin with the attachment of a cell surface integrin receptor to a nano-scale peptide sequence found within ECM proteins. After adhesion of a cell, multiple integrin receptors cluster into aggregates that recruit the assembly of several cytoplasmic and intercellular proteins into a complex termed the focal adhesion. Focal adhesions are on the order of $10 \mathrm{~nm}$ to $10 \mu \mathrm{m}$ and serve as crucial outside-to-inside signaling gateways that are necessary for proper cell function [2]. The micrometer- and nanometer-scale organization of surface proteins is expected to play a critical role in adhesion complex formation and function [3-7]. Seminal work in the area of cell adhesion studies in Whitesides' laboratory patterned cell adhesive domains on the cellular scale (10s of microns), demonstrating that by controlling the shape and size of the adhesive domain, the shape and degree of physical interaction between the surface and the cell could be controlled [8-11]. Since then, cell adhesion and cellular organization has been studied extensively on micrometerscale patterns [12-17]. However, studies of the influence of protein organization at the nanometer-scale have been limited due to a lack of a flexible, high-resolution submicron scale patterning technique that is capable of producing large enough patterned surfaces to examine a statistically relevant cell number [2].

Several techniques have been used to create surface patterns of proteins on the nanometer-scale for cellular studies [14, 17-24]. These techniques fall into four distinct categories including scanning probe, stamping, electron beam, and self-assembly $[14,17,23]$. Scanning probe techniques include nanografting, dip-pen lithography, conductive AFM, and other direct-write methods [25-30]. Stamping techniques include nanocontact printing, nanoimprint 


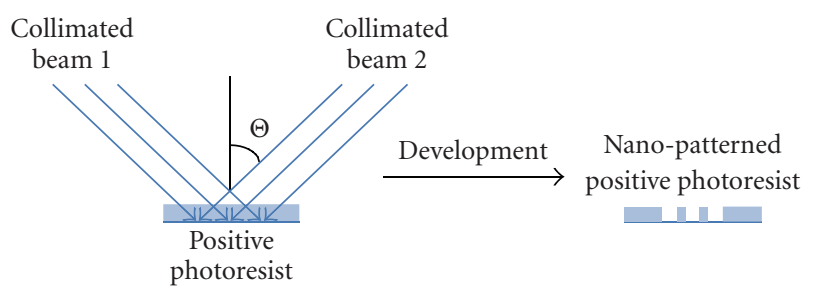

FIGURE 1: Schematic of the interference lithography process used to create submicron protein arrays.

lithography, decal transfer, and nanomolding [31-34]. Selfassembly techniques include particle lithography, polymerassisted templating and DNA-assisted assembly [3, 35, 36]. The above mentioned fabrication methods have been shown to be very useful to create patterns on the nano-scale, but are limited due to a high cost of fabrication or an inability to create arrays over areas large enough areas to examine statistically relevant numbers of cells [2, 23, 24]. An alternative to the methods listed above is interferometric lithography (IL), a subset of photolithography, which is capable of producing ordered nano-patterned arrays up to $4 \mathrm{~cm}^{2}$ efficiently and inexpensively without the use of a mask [37-39].

IL is the process of producing an interference pattern from two or more optical beams incident from different directions. This technique may be used on a thin film of photosensitive polymer (2D, where the thickness of the photoresist is much less than wavelength of the light used) or on a thick layer (3D, where the thickness of the photoresist is much less than wavelength of the light used). The interference of two coherent beams in two-beam IL creates a standing wave that can be recorded on the photosensitive polymer over an area of $4 \mathrm{~cm}^{2}$ in $\sim 5$-seconds. Figure 1 shows schematically how IL can be used to create a nano-patterned surface. The pitch, or period of the interference pattern, is governed by the following equation:

$$
\text { pitch }=\frac{\lambda}{2 n \sin (\theta)}
$$

where $\lambda$ is the wavelength of the beam source, $n$ is the index of refraction of the medium, and $\theta$ is the angle at which the two coherent beams are interfering. Features below $50 \mathrm{~nm}$ have been created using this technique [40]. Furthermore, the technique of IL has recently been used to create three dimensional surfaces to study the effects of micron-scale surface topography on human pulmonary fibroblast spreading and expression of inflammatory markers [41].

In this paper we describe the use of IL to produce a series of large-area $\left(4 \mathrm{~cm}^{2}\right)$ arrays of submicron domains that present a specific chemistry in patterned regions providing a versatile platform for the study of the effects of controlled alteration of the number, size, and spacing of focal adhesion formation during cell-material interactions. As shown in Figure 2, IL was used to pattern arrays of submicron cylindrical pillars on silicon waters. Gold was deposited on the arrays and the polymeric pillars removed,

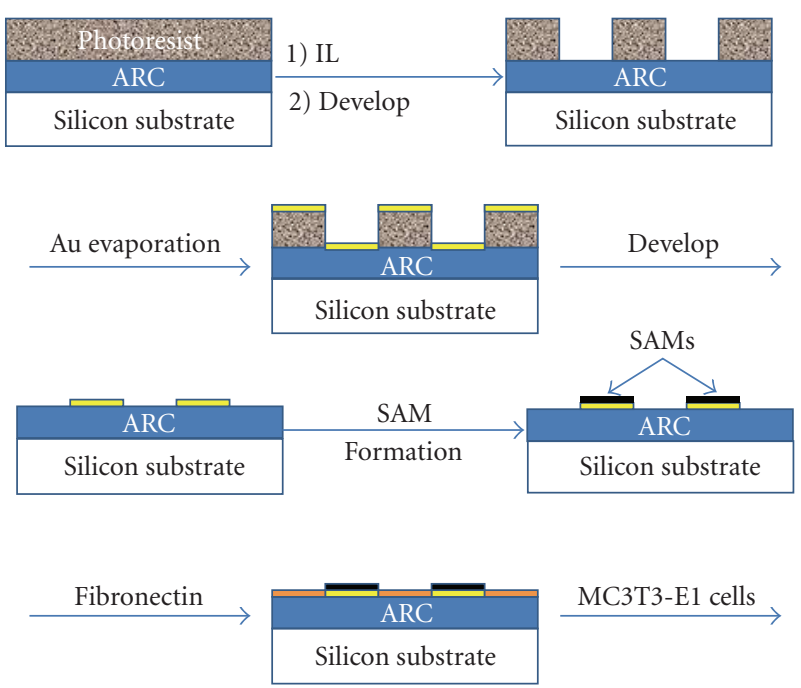

FIGURE 2: Schematic of the process of creating protein arrays.

creating a two-dimensional array of nano-scale domains in a gold layer. The gold surface was passivated using self-assembled monolayers (SAMs) of oligoethylene glycol (OEG) allowing for adsorption of the extracellular matrix protein fibronectin (FN) selectively to the nonpassivated array of nano-scale domains. For the studies presented here, the well-established murine osteoblast cell line MC3T3-E1 was chosen to demonstrate the availability of the adsorbed FN for cellular attachment through examination of cellular attachment and spreading on our patterned surfaces.

\section{Materials and Methods}

2.1. Fabrication of Nano-Patterned Structures. Silicon (Si) wafers (100) (100 mm, Siltec, Corp., Palo Alto, CA) were cleaned using an airbrush acetone spray and blow dried with $\mathrm{N}_{2}$ gas. The wafers were then dried on a hot plate at $110^{\circ} \mathrm{C}$ for $2 \mathrm{~min}$. A $100 \mathrm{~nm}$ thick layer of XHRiC-16 (Brewer Science, Inc., Rolla, MO) antireflective coating (ARC) was spun cast $(5000 \mathrm{rpm}, 30 \mathrm{~s})$ and hard baked at $175^{\circ} \mathrm{C}$ for 3 min. Positive photoresist (PR) (SPR-505A or SPR-510A diluted in EC11 solvent (1:1), Shipley Company, LLC, Marlborough, MA) was spun cast (4000 rpm, $30 \mathrm{~s})$ on top of the ARC followed by a soft bake at $90^{\circ} \mathrm{C}$ for $3 \mathrm{~min}$. The coated wafers were cleaved into quarters and then exposed using an interferometric lithography corner cube arrangement with a YAG-Nd laser $(\lambda=355 \mathrm{~nm}$, Infinity 40-100, Coherent, Inc., Santa Clara, CA) (Figure 3). In this simple arrangement, an expanded collimated laser beam is folded onto itself using a $90^{\circ}$ geometry [37]. Cylindrical photoresist pillars were created by exposing the wafers twice for 5-seconds with the second exposure rotated $90^{\circ}$ from the first $[37,42]$. Three substrate configurations were created using different interference angles $\left(\theta=36.3^{\circ}, 23.2^{\circ}, 13.7^{\circ}\right.$, yielding pitches of $300 \mathrm{~nm}, 450 \mathrm{~nm}$, and $750 \mathrm{~nm}$, resp.). After exposure, each sample was soft baked at $110^{\circ} \mathrm{C}$ for $1 \mathrm{~min}$ and the developer (undiluted MF702 developer, Shipley Co.) was 


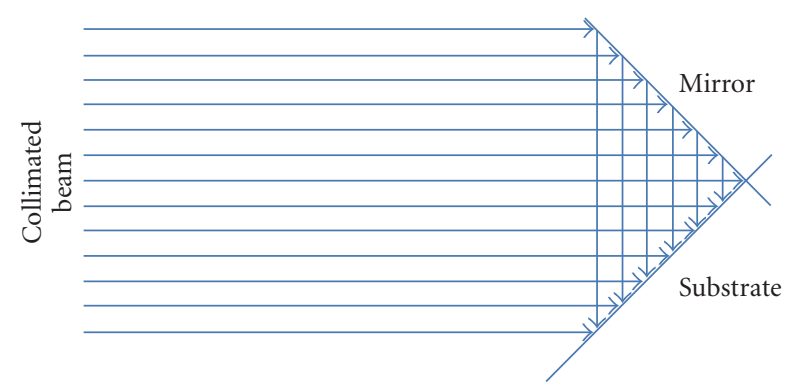

Figure 3: Corner cube IL arrangement used to create large-area arrays.

added dropwise to form a puddle on the surface over $45 \mathrm{~s}$. Finally the samples were rinsed with deionized water and blown dry with $\mathrm{N}_{2}$ gas.

The developed chips were placed in an e-beam evaporator (Consolidated Vacuum Corp., Rochester, NY) where a $3 \mathrm{~nm}$ layer of $\mathrm{Cr}$ was deposited on top of the patterned substrate followed by the deposition of $30 \mathrm{~nm}$ of gold (99.999\%, Plasmaterials, Inc., Livermore, CA). After metal evaporation, the remaining photoresist pillars were lifted off by sonicating the Cr/gold-covered chips in acetone for $30 \mathrm{~min}$, leaving an array of nanometer-scale ARC patches in the gold covered surface.

2.2. Nanometer-Scale Protein Adhesive Domains. The patterned chips were further cleaved into $1 \mathrm{~cm}^{2}$ squares. The gold covered surface was functionalized by incubating the substrate in a $1 \mathrm{mM}$ solution of $\mathrm{HS}\left(\mathrm{CH}_{2}\right)_{11}\left(\mathrm{OCH}_{2}-\right.$ $\left.\mathrm{CH}_{2}\right)_{3} \mathrm{OH}$, 2-(2-(2-(11-mercaptoundecyloxy)ethoxy)ethoxy)ethanol, (OEG, 95\%, Sigma-Aldrich, St. Louis, MO) in ethanol for $24 \mathrm{hrs}$. To create protein-adhesive domains, fibronectin (FN) from bovine plasma was adsorbed onto the ARC patches by incubating a FN solution $(5 \mu \mathrm{g} / \mathrm{mL}$, in Dulbecco's Phosphate Buffered Saline (PBS), GIBCO, Invitrogen Corp., Carlsbad, CA) for $1 \mathrm{hr}$ at $4^{\circ} \mathrm{C}$ on an orbital shaker.

2.3. Microscopy. Topography of the substrates with bound OEG was imaged with a scanning probe microscope/atomic force microscope (tip) (Digital Instruments CP-II, Veeco, Plainview, New York) equipped with a Veeco Si tip in tapping mode. After thiol adsorption the samples were air dried and mounted on an aluminum holder for AFM scanning. Images of the pillared and the gold coated surfaces were taken using a field-emission scanning electron microscope (SEM) (Hitachi S5200 Nano SEM, Pleasanton, CA). To image cell spreading using SEM, substrates with adherent cells were prepared by fixing in $2.5 \%$ glutaraldehyde for $45 \mathrm{~min}$ at room temperature and then dehydrated with increasing amounts of ethyl alcohol (30\%-100\%, 5 min each), rinsing with PBS after each ethanol step.

2.4. Characterization of Protein-Adhesive Domains. Gold labeled antibodies (Nanogold conjugates, Nanoprobes, Inc., Stony Brook, NY) were used to visualize proteins bound to the patterned substrates. After FN adsorption, the surfaces were rinsed with PBS to wash off any weakly adsorbed FN. The substrates were incubated in a solution of antiFN primary antibodies in PBS (1:400, AB2047, Millipore Corp., Billerica, MA) for $1 \mathrm{hr}$ at $4^{\circ} \mathrm{C}$ on an orbital shaker and washed with PBS after antibody binding. Secondary gold-labeled antibodies in PBS $(1: 400)$ were incubated with the substrates to allow for binding to the primary antibody following the same procedure as the described above. GoldEnhance EM (Nanoprobes Inc.) was applied for 5 min following the manufacturer's recommended protocol to increase the size of the gold-labeled antibodies for better visualization with electron microscopy.

2.5. Cell Culture. The murine osteoblast cell line MC3T3E1 (CRL-2593, ATCC, Manassas, VA) was used to demonstrate accessibility of the adsorbed FN for cellular attachment through attachment, viability, and spreading studies. These cells were chosen as they are a well-established, widely used cell line. Before seeding, cells were maintained in $\alpha$-Minimum Essential Medium ( $\alpha$-MEM, GIBCO, Invitrogen Corp.) supplemented with $10 \%$ fetal bovine serum (FBS, GIBCO, Invitrogen Corp.) and 1\% penicillinstreptomycin (GIBCO, Invitrogen Corp.) and passaged every 3 days using standard techniques. To passage, adherent cells were rinsed with PBS, enzymatically lifted through incubation with $0.25 \%$ trypsin- $2,2^{\prime}, 2^{\prime \prime}, 2^{\prime \prime \prime}$ - (ethane1,2diyldinitrilo)tetraacetic acid (trypsin-EDTA, Fisher Scientific, Waltham, MA) for $10 \mathrm{~min}$, and equally divided among three new flasks (T-75, Fisher Scientific). Prior to cell seeding, cells were enzymatically lifted and counted with a hemocytometer. The cells were seeded onto the surfaces at a density of $2.5 \times 10^{4}$ cells $/ \mathrm{cm}^{2}$ and incubated at $3{ }^{\circ} \mathrm{C}$ and $5 \%$ $\mathrm{CO}_{2}$ in a humidified environment.

2.6. Cell Studies. To determine cellular attachment affinity for each of the array component materials, cells were seeded on flat, nonpatterned surfaces of ARC after incubation in a fibronectin solution as described for the patterned surfaces (ARC + FN), ARC without incubation prior to cell seeding (ARC), OEG SAM functionalized ARC incubated in a FN solution (OEG + FN), and OEG alone (OEG). Glass microscope slides without incubation in a FN solution was used as a positive control (Glass). After $4 \mathrm{hrs}$ of incubation, cell-seeded substrates were rinsed twice with PBS to remove any unattached cells. Cell number was determined using the CeliTitre-Glo Luminescent Cell Viability Assay Kit (G7S71, Promega, San Luis Obispo, CA). This assay quantitates the amount of ATP released from the adherent cells after incubation in a cell lysis buffer. The measured luminescence is then compared to a standard curve created with known numbers of cells.

On the array surfaces, a LIVE/DEAD Viability/Cytotoxicity Assay Kit (L-3224, Invitrogen, Carlsbad, CA) was used according to manufacturer's instructions to image and assess cellular viability on the patterned substrates. For this controlled study, ARC surfaces were used as the positive control. After 4 hrs of culture, cells were rinsed with PBS 
twice. Cells were then treated with a calcein acetoxymethyl ester: ethidium homodimer-1 solution $(2 \mu \mathrm{M}: 4 \mu \mathrm{M})$ and incubated for $30 \mathrm{~min}$ in the dark at room temperature. Ubiquitous presence of esterase activity on live cells converts calcein AM into green fluorescent calcein. Ethidium homodimer-1 penetrates damaged membranes of dead cells and fluoresces red as it binds nucleic acids. Following incubation, cells were rinsed with PBS three times and fixed in $4 \%$ formaldehyde in PBS for 10 min. The substrates were mounted on a microscope slide using antifade mounting solution (5013, Millipore Corp., Billerica, MA) and the entire surface was imaged using a confocal microscope (Zeiss LSM 51O-META, Thornwood, NY). Cell counts of live and dead cells for three samples were used for viability calculations.

2.7. Statistical Analysis. Results were analyzed using the Kruskal-Wallis one-way nonparametric analysis of variance (ANOVA) with values of $p<0.05$ considered statistically significant.

\section{Results and Discussion}

3.1. Fabrication of Arrays of SubMicron Protein Domains. Silicon wafers were treated initially with a layer of ARC to prevent reflection from the Si substrate back onto the photoresist. Positive photoresists formulations SPR505A and SPR510A were spuncast onto the ARC-treated Si wafers. A corner-cube arrangement was used to create 2D square arrays (Figure 3). The square array was obtained by exposing the photoresist twice for 5-seconds, with the second exposure at $90^{\circ}$ from the first. The resulting structure is a $2 \mathrm{D}$ array of cylindrical posts with diameter and pitch determined by the angle of interference, $\theta[37,42]$. Following exposure and development, the cylindrical posts on the ARC were visualized using SEM. Figure 4 shows post arrays for interference angles of $36.3^{\circ}, 23.2^{\circ}$, and $13.7^{\circ}$ created with an ultraviolet beam source $(\lambda=355 \mathrm{~nm})$ in $\operatorname{air}(n=1)$. Figure 4(a) shows an SEM micrograph of posts with a diameter close to $140 \mathrm{~nm}$ and a pitch of $300 \mathrm{~nm}$, created by an angle of interference of $36.3^{\circ}$. As the angle of interference was reduced to $23.2^{\circ}$ and then $13.7^{\circ}$ the pitch increased from $450 \mathrm{~nm}$ to $750 \mathrm{~nm}$, respectively (Figures 4(b) and 4(c)). With our interference lithography setup, as the pitch increased, the post diameter also increased, with a pitch-to-post ratio remaining at $\sim 2: 1$.

A $3 \mathrm{~nm}$ chromium adhesion layer followed by $30 \mathrm{~nm}$ layer of gold was deposited on the surfaces of the patterned substrates. Acetone was used to selectively remove the cylindrical posts, exposing submicron sized ARC patches in a gold field. Figure 5 presents scanning electron micrograph images of surfaces after removal of the photoresists posts for the three interference angles examined, $36.3^{\circ}$ (Figure 5(a)), $23.2^{\circ}$ (Figure 5(b)), and $13.7^{\circ}$ (Figure 5(c)). All three images show the presence of ordered arrays in the gold surface with complete removal of the photoresist pillars. Scanning electron micrographs from three different samples for each pitch size were used to determine and average the pitch distance and patch diameter, with ten random pitches/patches

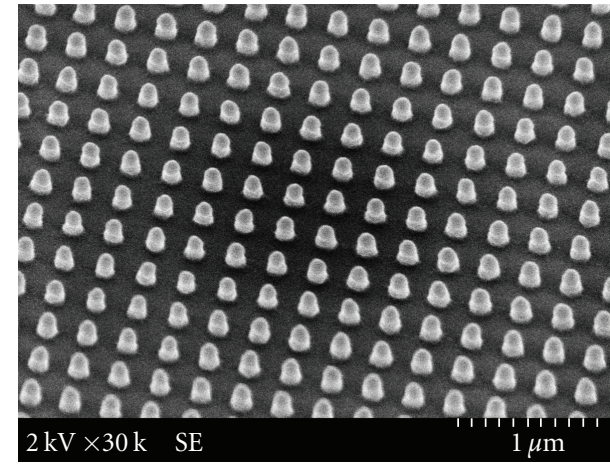

(a)

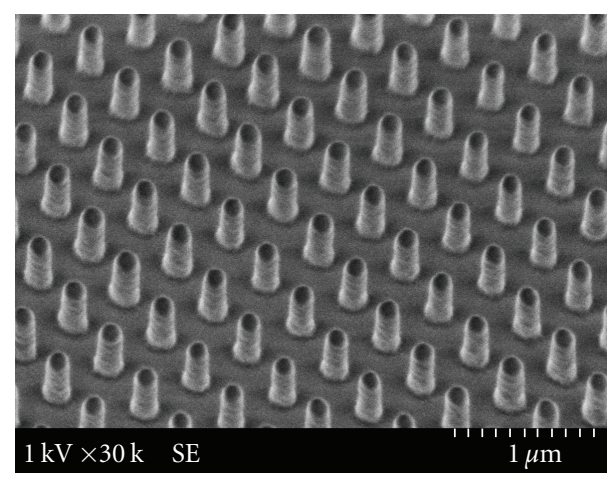

(b)

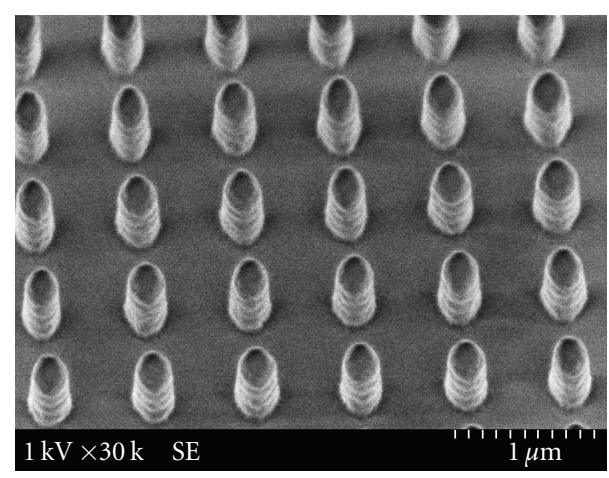

(c)

FIgURE 4: SEM micrographs of 2D arrays of posts. (a) $300 \mathrm{~nm}$ pitch $\left(\theta=36.3^{\circ}\right)$. (b) $450 \mathrm{~nm}$ pitch $\left(\theta=23.2^{\circ}\right)$. (c) $750 \mathrm{~nm}$ pitch $\left(\theta=13.7^{\circ}\right)$. Photoresist posts are created after a $2 \mathrm{D}$ exposure of two-beam IL.

measured per sample. From these measurements, individual patch size and total cell adhesive area per square micron were calculated (Table 1). While the number of domains per square micron decreased with increasing patch diameter and pitch, the total area of all cell adhesive domains per square micron did not change significantly (ANOVA $p=0.096$ ). Because of this, these surfaces are ideal for isolating the effects of variations in the number, size, and spacing of attachment sites a cell is exposed to on a surface from changes in the total attachment area. 
To passivate the background, the gold field was treated with an ethanolic solution of 2-(2-(2-(11-mercaptoundecyloxy)ethoxy)ethoxy)ethanol (OEG). It has been previously shown that self-assembled monolayers (SAMs) of oligoethylene glycol terminated thiols assembled on gold surfaces do not allow protein binding. Because cells require the presence of proteins in their correct conformation in order to attach to a surface, the OEG SAMs do not allow for or support cellular attachment $[9,43,44]$. The submicronscale domains on the surfaces as well as the homogeneity of the OEG-SAM layer was visualized with AFM. Figure 6 shows a representative AFM image of a $4 \mu \mathrm{m}^{2}$ area of a surface with a pitch of $300 \mathrm{~nm}\left(\theta=36.3^{\circ}\right.$, patch diameter of $150 \mathrm{~nm}$ ) after SAM formation. Because the SAMs bound selectively on the gold surface and not the noncoated submicron domains, the domains can be distinguished on sample as regularly ordered depressions in SAM surface. During fabrication, $37 \mathrm{~nm}$ thick layer of metal was deposited on the surfaces. The AFM image shows a consistent layer of material approximately $40 \mathrm{~nm}$ tall in all areas except the circular domains, which is expected as a OEG SAM layer is approximately $2 \mathrm{~nm}$ thick [45].

To render the ARC patches cell adhesive, the patterned substrates were incubated with FN, an extracellular matrix protein known to bind with integrins expressed by the murine osteoblast cell line MC3T3-E1 [46]. Scanning electron microscope images were used to locate $\mathrm{FN}$ on the surfaces after incubation with the protein solution. To allow for clearer imaging of the adsorbed proteins and ensure differentiation between the FN and other surface features, samples were exposed to a solution of primary antibodies specific to FN followed by labeling of the primary with secondary antibodies labeled with gold nanoparticles. The gold label was enhanced with the use of the gold deposition solution GoldEnhance EM (Nanoprobes, Inc.). Figure 7 shows the enhanced gold-labeled antibodies, indicating the presence of $\mathrm{FN}$, located at the ARC domains and not throught the OEG SAM surface. In the SEM images the protein appears to be localized at the edges of the ARC domains. This attachment pattern within the ARC domain may be an artifact of the dehydration process the samples must undergo to allow visualization via SEM. As the aqueous phase evaporates out of the pores created by the SAMs, the protein is forced the edges and remains there upon complete dehydration.

\subsection{Cellular Attachment to Individual Material Components.} Before seeding cells on the arrays, studies were performed to examine the attachment affinity of the cells to each of the material components of the patterned substrates. Figure 8 shows the results of attachment studies of the murine osteoblast cell line MC3T3-E1 on nonpatterned ARC surfaces after incubation with FN, ARC alone, OEG SAMs after incubation with FN, OEG SAMs alone, and glass substrates. Cellular attachment was statistically greater on ARC surfaces after incubation with FN than any other treatment group examined. The OEG SAMs exhibited minimal cell attachment regardless of incubation with

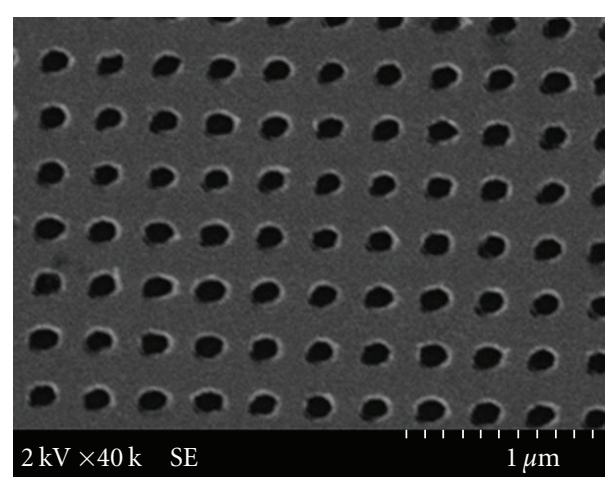

(a)

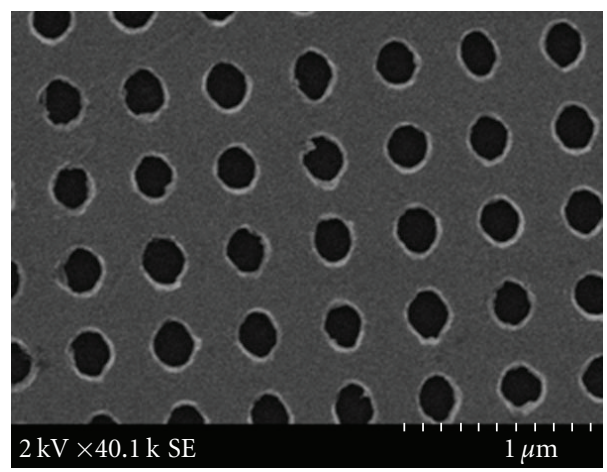

(b)

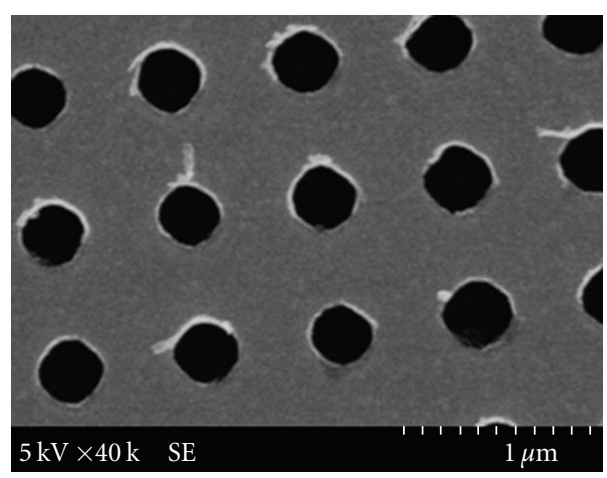

(c)

FIGURE 5: SEM micrographs of resulting patterned submicron-sized ARC patches after photoresist lift-off. (a) $300 \mathrm{~nm}$ pitch. (b) $450 \mathrm{~nm}$ pitch. (c) $750 \mathrm{~nm}$ pitch.

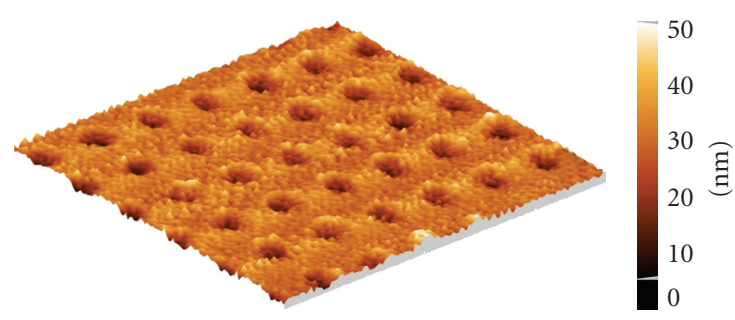

Figure 6: AFM scan of a representative area $\left(4 \mu \mathrm{m}^{2}\right)$ of a $100 \mathrm{~nm}$ domain array after OEG adsorption. The metal/SAM layer is found to be approximately $40 \mathrm{~nm}$ above the ARC surface as expected. The SAM surface is a consistent height, showing a lack of defects. 
TABle 1: Patch diameter related to the pitch distance.

\begin{tabular}{|c|c|c|c|c|c|c|c|}
\hline $\begin{array}{l}\text { Angle of } \\
\text { interference }\end{array}$ & $\begin{array}{l}\text { Theoretical } \\
\text { pitch }(\mathrm{nm})\end{array}$ & $\begin{array}{c}\text { Theoretical } \\
\text { domain } \\
\text { diameter }(\mathrm{nm})\end{array}$ & $\begin{array}{l}\text { Measured } \\
\text { pitch }(\mathrm{nm})\end{array}$ & $\begin{array}{c}\text { Measured } \\
\text { domain } \\
\text { diameter }(\mathrm{nm})\end{array}$ & $\begin{array}{c}\text { Area per } \\
\text { domain } \\
* 10^{-2}\left(\mu \mathrm{m}^{2}\right)\end{array}$ & $\begin{array}{c}\text { Number of } \\
\text { Domains per } \\
\mu \mathrm{m}^{2}\end{array}$ & $\begin{array}{l}\text { Total domain } \\
\text { area per } \mu \mathrm{m}^{2} \\
\left(* 10^{-2}\right)\left(\mu \mathrm{m}^{2}\right)\end{array}$ \\
\hline $36.3^{\circ}$ & 300 & 150 & $304 \pm 8$ & $140 \pm 10$ & $1.5 \pm 0.2$ & 9 & $14 \pm 1$ \\
\hline $23.2^{\circ}$ & 450 & 225 & $460 \pm 20$ & $200 \pm 30$ & $3.1 \pm 0.6$ & 4 & $13 \pm 3$ \\
\hline $13.7^{\circ}$ & 750 & 375 & $750 \pm 20$ & $350 \pm 20$ & $9.6 \pm 0.8$ & 1 & $10 \pm 1$ \\
\hline
\end{tabular}

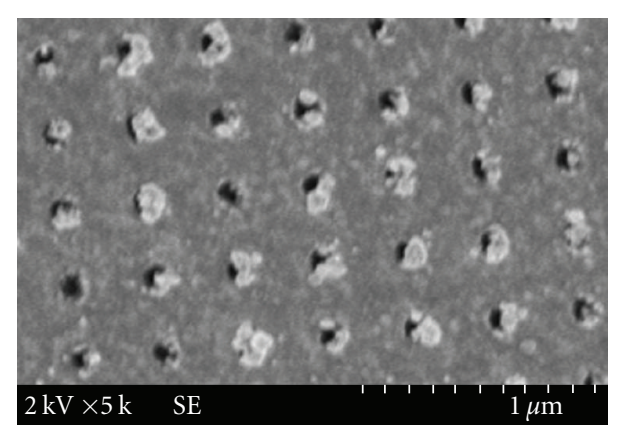

FIgURE 7: SEM micrograph of $100 \mathrm{~nm}$ domain array after SAM formation and FN adsorption. Gold nanopartide-Iabeled antibodies and a gold enhance solution was used to visualize location of FN on the surface. Note that the FN has selectively adsorbed to the submicron domains and cannot be found throughout the SAM surface.

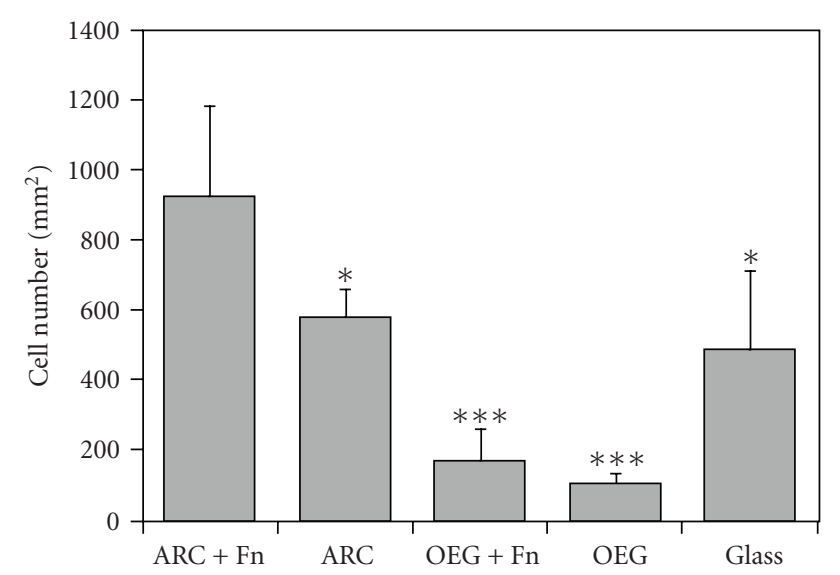

FIGURE 8: Cellular attachment on protein array component materials (positive control: glass) $\left({ }^{*} p<0.05,{ }^{* * *} p<0.001\right)$.

fibronectin. These results were expected as previous studies have shown OEG SAMs fabricated with 2-(2-(2-(11mercaptoundecyloxy)ethoxy)ethoxy)ethanol resist protein adsorption due to tight packing of the OEG chains with minimal defects [9]. Without proteins with which to interact on the OEG SAM surface, cells cannot attach. These results suggest that cells will adhere selectively to the protein domains of our arrays. The increased cellular attachment to the ARC surface post-attachment compared to either of the OEG surfaces is likely due to nonspecific adsorption of the proteins present in the cell culture media.
3.3. Availability of Adsorbed FN for Cell Attachment on Protein Arrays. To determine whether the FN of the adsorbed protein array was accessible to cells, arrays were seeded with a murine osteoblast cell line. These cells were chosen as a model cell line to verify cellular attachment and viability on our arrays as they are well characterized and their behavior well studied. The cells were allowed to attach and spread on $1 \mathrm{~cm}^{2}$ arrays over $12 \mathrm{hrs}$ followed by fluorescent staining with a LIVE/DEAD Viability/Cytotoxicity Assay. This assay stains live cells green and dead cells red. Confocal images of the stained cells on arrays and as well as nonpatterned ARC-coated Si wafers after incubation with FN are presented in Figures 9(a) and 9(b), respectively. The flat ARC-coated FN surfaces were used as positive controls in order to determine if the patterned surfaces did not allow for cellular attachment. Both surfaces show good attachment and spreading with no evidence of post-attachment cell death. Quantification of the cell numbers showed no differences in cell number between the pattern substrates and the positive controls (data not shown).

While cellular attachment and spreading could be visualized with a fluorescent microscope, scanning electron microscopy was necessary to directly examine the cell/material interactions. Scanning electron microscopy allows for the imaging of the cells and material surface features directly at a much greater magnification than traditional fluorescent microscopy. Figure 10 presents representative images of cells on the arrays 4 hrs after seeding. As seen in the fluorescent images, the cells have attached and spread on the arrays. Philipodia are seen spreading out from the cell bodies, following paths through the protein arrays (Figures 10(a) and 10(b)). At higher magnifications, the cells can be seen probing and exploring the submicron domains (Figures 10(b) and 10(d)).

\section{Conclusions}

Interference lithography was implemented successfully to create large-scale protein arrays. IL is an attractive alternative to many existing techniques as it can create ordered structures without the need for a phase mask or stamp and can create arrays up to $4 \mathrm{~cm}^{2}$ with just two 5-second exposure steps. IL was used to create arrays of submicron diameter pillars on ARC-coated silicon wafers. These surfaces were further treated to create arrays of adsorbed FN in a passivated background. Murine osteoblasts (MC3T3-E1) were used to demonstrate the availability of FN for cellular interactions through cellular attachment and spreading studies on the protein arrays. Just four hours after seeding, cells were 


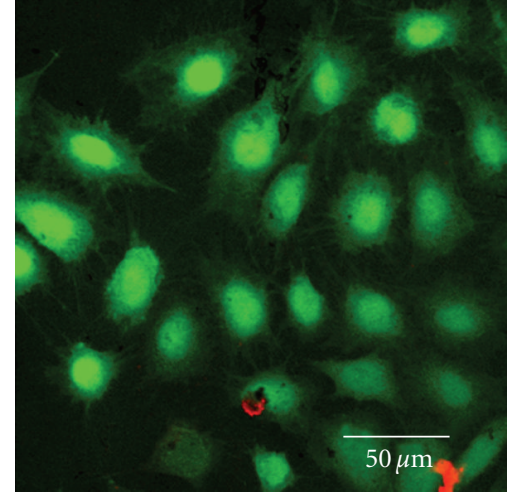

(a)

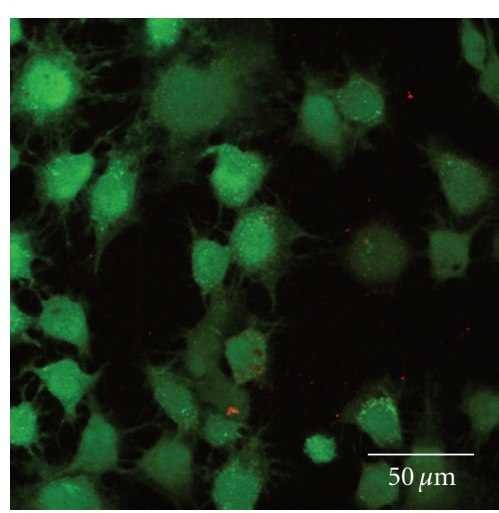

(b)

Figure 9: Fluorescent images of MC3T3 cells $12 \mathrm{hrs}$ after seeding on (a) positive control ARC-coated Si wafer with adsorbed FN and (b) $100 \mathrm{~nm}$ domain protein array. Using the Live/Dead Viability Assay, live cells appear green whereas dead cells appear red.

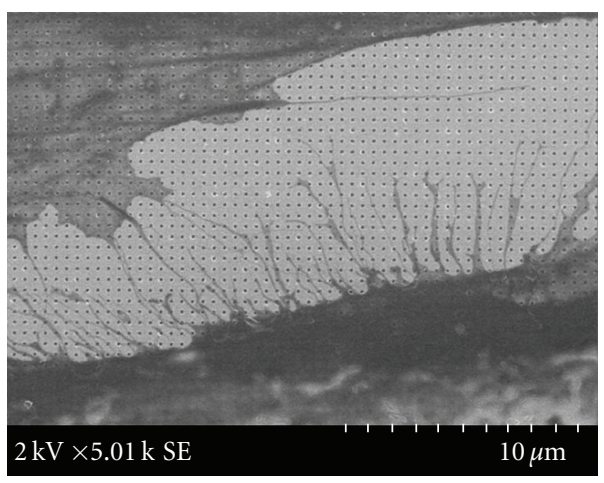

(a)

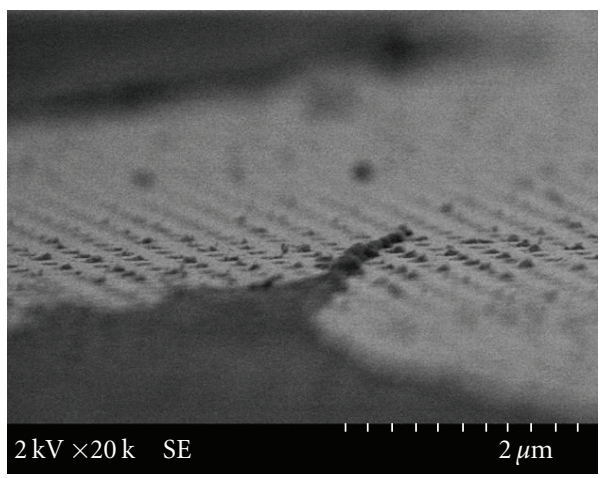

(c)

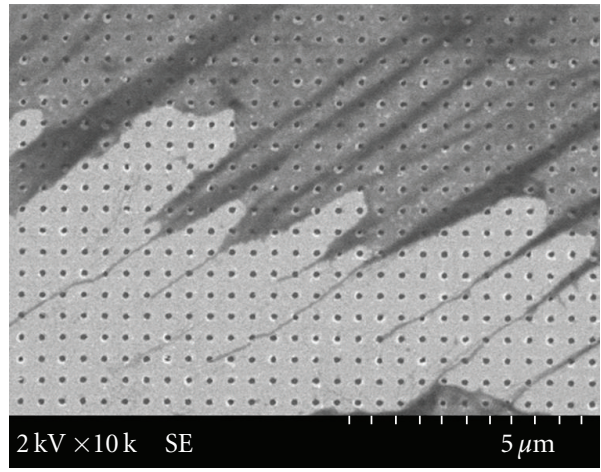

(b)

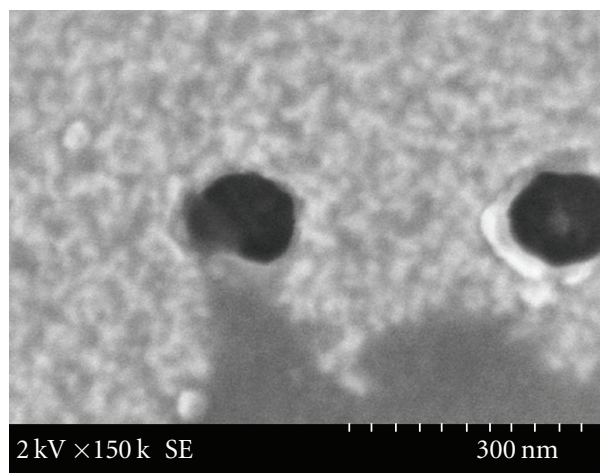

(d)

FIGURE 10: Representative scanning electron micrographs of MC3T3 cells on protein arrays. (a) and (b) show cell attachment and spreading; (c) and (d) demonstrate extension of cellular processes as cells probe the surface and selectively attach to protein domains.

shown to be extending projections, connecting the cell to the adhesive domains on the patterned surfaces. These patterned cell adhesive domain arrays offer a cell culture platform to study the effects of systematic manipulation of size and distribution of cell/material interaction points on cellular processes.

\section{Acknowledgments}

The authors would like to thank Dr. Gabriel P. Lopez for assistance with the development of this project. Financial support was provided by a UNM Main Campus Research Allocation Committee (RAC) grant, an NSF PREM program 
Grant no. DMR-0611616, an NSF Graduate Research Fellowship (UAM) and an NSF IGERT Fellowship in Nanoscience and Microsystems as part of Grant no. DGE-OS04276 (UAM).

\section{References}

[1] M. M. Stevens and J. H. George, "Exploring and engineering the cell surface interface," Science, vol. 310, no. 5751, pp. 11351138, 2005.

[2] D. Pesen and D. B. Haviland, "Modulation of cell adhesion complexes by surface protein pattern," ACS Applied Materials \& Interfaces, vol. 1, no. 3, pp. 543-548, 2009.

[3] M. Arnold, V. C. Hirschfeld-Warneken, T. Lohmüller et al., "Induction of cell polarization and migration by a gradient of nanoscale variations in adhesive ligand spacing," Nano Letters, vol. 8, no. 7, pp. 2063-2069, 2008.

[4] J. S. Burmeister, V. Z. McKinney, W. M. Reichert, and G. A. Truskey, "Role of endothelial cell-substrate contact area and fibronectin-receptor affinity in cell adhesion to HEMA/EMA copolymers," Journal of Biomedical Materials Research, vol. 47, no. 4, pp. 577-584, 1999.

[5] B. G. Keselowsky, D. M. Collard, and A. J. García, "Integrin binding specificity regulates biomaterial surface chemistry effects on cell differentiation," Proceedings of the National Academy of Sciences of the United States of America, vol. 102, no. 17, pp. 5953-5957, 2005.

[6] D. M. Pirone, W. Liu, S. Raghavan, L. Romer, and C. S. Chen, "Focal adhesion kinase controls shape-dependant endothelial cell proliferation," Molecular Biology of the Cell, vol. 15, p. 14, 2004.

[7] D. Thid, M. Bally, K. Holm et al., "Issues of ligand accessibility and mobility in initial cell attachment," Langmuir, vol. 23, no. 23, pp. 11693-11704, 2007.

[8] R. Singhvi, A. Kumar, G. P. Lopez et al., "Engineering cell shape and function," Science, vol. 264, no. 5159, pp. 696-698, 1994.

[9] M. Mrksich and G. M. Whitesides, "Using self-assembled monolayers to understand the interactions of man-made surfaces with proteins and cells," Annual Review of Biophysics and Biomolecular Structure, vol. 25, pp. 55-78, 1996.

[10] C. S. Chen, M. Mrksich, S. Huang, G. M. Whitesides, and D. E. Ingber, "Geometric control of cell life and death," Science, vol. 276, no. 5317, pp. 1425-1428, 1997.

[11] C. S. Chen, M. Mrksich, S. Huang, G. M. Whitesides, and D. E. Ingber, "Micropatterned surfaces for control of cell shape, position, and function," Biotechnology Progress, vol. 14, no. 3, pp. 356-363, 1998.

[12] R. Barbucci, S. Lamponi, D. Pasqui, A. Rossi, and E. Weber, "Micropatterned polysaccharide surfaces via laser ablation for cell guidance," Materials Science and Engineering C, vol. 23, no. 3, pp. 329-335, 2003.

[13] B. G. Chung, L. Kang, and A. Khademhosseini, "Microand nanoscale technologies for tissue engineering and drug discovery applications," Expert Opinion on Drug Discovery, vol. 2, no. 12, pp. 1653-1668, 2007.

[14] A. del Campo and E. Arzt, "Fabrication approaches for generating complex micro- and nanopatterns on polymeric surfaces," Chemical Reviews, vol. 108, no. 3, pp. 911-945, 2008.

[15] S. Raghavan and C. S. Chen, "Micropatterned environments in cell biology," Advanced Materials, vol. 16, no. 15, pp. 13031313, 2004.
[16] C. J. Shen, J. P. Fu, and C. S. Chen, "Patterning cell and tissue function," Cellular and Molecular Bioengineering, vol. 1, no. 1, pp. 15-23, 2008.

[17] A. J. Torres, M. Wu, D. Holowka, and B. Baird, "Nanobiotechnology and cell biology: micro- and nanofabricated surfaces to investigate receptor-mediated signaling," Annual Review of Biophysics, vol. 37, pp. 265-288, 2008.

[18] M. Arnold, M. Schwieder, J. Blümmel et al., "Cell interactions with hierarchically structured nano-patterned adhesive surfaces," Soft Matter, vol. 5, no. 1, pp. 72-77, 2009.

[19] C. C. Berry, A. S. G. Curtis, R. O. C. Oreffo, H. Agheli, and D. S. Sutherland, "Human fibroblast and human bone marrow cell response to lithographically nanopatterned adhesive domains on protein rejecting substrates," IEEE Transactions on Nanobioscience, vol. 6, no. 3, pp. 201-209, 2007.

[20] H. E. Gaubert and W. Frey, "Highly parallel fabrication of nanopatterned surfaces with nanoscale orthogonal biofunctionalization imprint lithography," Nanotechnology, vol. 18, no. 13, Article ID 135101, 2007.

[21] S. E. A. Gratton, S. S. Williams, M. E. Napier et al., "The pursuit of a scalable nanofabrication platform for use in material and life science applications," Accounts of Chemical Research, vol. 41, no. 12, pp. 1685-1695, 2008.

[22] S. G. Kumbar, M. D. Kofron, L. S. Nair, and C.T. Laurencin, "Cell behavior toward nanostructured surfaces," in Biomedical Nanostructures, K. E. Gonsalves, Ed., pp. 261-295, John Wiley \& Sons, Hoboken, NJ, USA, 2008.

[23] E. Engel, A. Michiardi, M. Navarro, D. Lacroix, and J. A. Planell, "Nanotechnology in regenerative medicine: the materials side," Trends in Biotechnology, vol. 26, no. 1, pp. 3947, 2008.

[24] K. L. Christman, V. D. Enriquez-Rios, and H. D. Maynard, "Nanopatterning proteins and peptides," Soft Matter, vol. 2, no. 11, pp. 928-939, 2006.

[25] R. K. Smith, P. A. Lewis, and P. S. Weiss, "Patterning selfassembled monolayers," Progress in Surface Science, vol. 75, no. 1-2, pp. 1-68, 2004.

[26] M. Liu, N. A. Amro, and G.-Y. Liu, "Nanografting for surface physical chemistry," Annual Review of Physical Chemistry, vol. 59, pp. 367-386, 2008.

[27] G.-Y. Liu, S. Xu, and Y. Qian, "Nanofabrication of selfassembled monolayers using scanning probe lithography," Accounts of Chemical Research, vol. 33, no. 7, pp. 457-466, 2000.

[28] K. Salaita, Y. Wang, and C. A. Mirkin, "Applications of dippen nanolithography," Nature Nanotechnology, vol. 2, no. 3, pp. 145-155, 2007.

[29] R. A. Barry III, R. F. Shepherd, J. N. Hanson, R. G. Nuzzo, P. Wiltzius, and J. A. Lewis, "Direct-write assembly of 3D hydrogel scaffolds for guided cell growth," Advanced Materials, vol. 21, no. 23, pp. 2407-2410, 2009.

[30] K.-B. Lee, S.-J. Park, C. A. Mirkin, J. C. Smith, and M. Mrksich, "Protein nanoarrays generated by dip-pen nanotithography," Science, vol. 295, no. 5560, pp. 1702-1705, 2002.

[31] D. Qin, Y. Xia, and G. M. Whitesides, "Soft lithography for micro- and nanoscale patterning," Nature Protocols, vol. 5, no. 3, pp. 491-502, 2010.

[32] Y. Xia and G. M. Whitesides, "Soft lithography," Angewandte Chemie. International Edition, vol. 37, no. 5, pp. 551-575, 1998.

[33] J. N. Hanson, M. J. Motala, M. L. Heien, M. Gillette, J. Sweedler, and R. G. Nuzzo, "Textural guidance cues for controlling process outgrowth of mammalian neurons," Lab on a Chip, vol. 9, no. 1, pp. 122-131, 2009. 
[34] P. Kim, B. K. Lee, H. Y. Lee, T. Kawai, and K. Y. Suh, "Molded nanowell electrodes for site-selective single liposome arrays," Advanced Materials, vol. 20, no. 1, pp. 31-36, 2008.

[35] S. H. Park, P. Yin, Y. Liu, J. H. Reif, T. H. Labean, and H. Yan, "Programmable DMA self-assemblies for nanoscale organization of ligands and proteins," Nano Letters, vol. 5, no. 4, pp. 729-733, 2005.

[36] H. Yan, S. H. Park, G. Finkelstein, J. H. Reif, and T. H. LaBean, "DNA-templated self-assembly of protein arrays and highly conductive nanowires," Science, vol. 301, no. 5641, pp. 18821884, 2003.

[37] S. R. J. Brueck, "Optical and interferometric lithographynanotechnology enablers," Proceedings of the IEEE, vol. 93, no. 10, pp. 1704-1721, 2005.

[38] J. H. Moon, J. Ford, and S. Yang, "Fabricating threedimensional polymeric photonic structures by multi-beam interference lithography," Polymers for Advanced Technologies, vol. 17, no. 2, pp. 83-93, 2006.

[39] J.-H. Jang, C. K. Ullal, M. Maldovan et al., "3D microand nanostructures via interference lithography," Advanced Functional Materials, vol. 17, no. 16, pp. 3027-3041, 2007.

[40] M. Switkes, T. M. Bloomstein, and M. Rothschild, "Patterning of sub-50 nm dense features with space-invariant $157 \mathrm{~nm}$ interference lithography," Applied Physics Letters, vol. 77, no. 20, pp. 3149-3151, 2000.

[41] F. Yu, F. Mücklich, P. Li et al., "In vitro cell response to a polymer surface micropatterned by laser interference lithography," Biomacromolecules, vol. 6, no. 3, pp. 1160-1167, 2005.

[42] S. H. Zaidi and S. R. J. Brueck, "Multiple-exposure interfereometric lithography," Journal of Vacuum Science \& Technology $B$, vol. 11, no. 3, pp. 658-666, 1993.

[43] R. Barbucci, S. Lamponi, A. Magnani, F. M. Piras, A. Rossi, and E. Weber, "Role of the Hyal-Cu (II) complex on bovine aortic and lymphatic endothelial cells behavior on microstructured surfaces," Biomacromolecules, vol. 6, no. 1, pp. 212-219, 2005.

[44] M. W. A. Skoda, F. Schreiber, R. M. J. Jacobs et al., "Protein density profile at the interface of water with oligo(ethylene glycol) self-assembled monolayers," Langmuir, vol. 25, no. 7, pp. 4056-4064, 2009.

[45] X. Qian, S. J. Metallo, I. S. Choi, H. Wu, M. N. Liang, and G. M. Whitesides, "Arrays of self-assembled monolayers for studying inhibition of bacterial adhesion," Analytical Chemistry, vol. 74, no. 8, pp. 1805-1810, 2002.

[46] R. G. Lebaron and K. A. Athanasiou, "Extracellular matrix cell adhesion peptides: functional applications in orthopedic materials," Tissue Engineering, vol. 6, no. 2, pp. 85-103, 2000. 

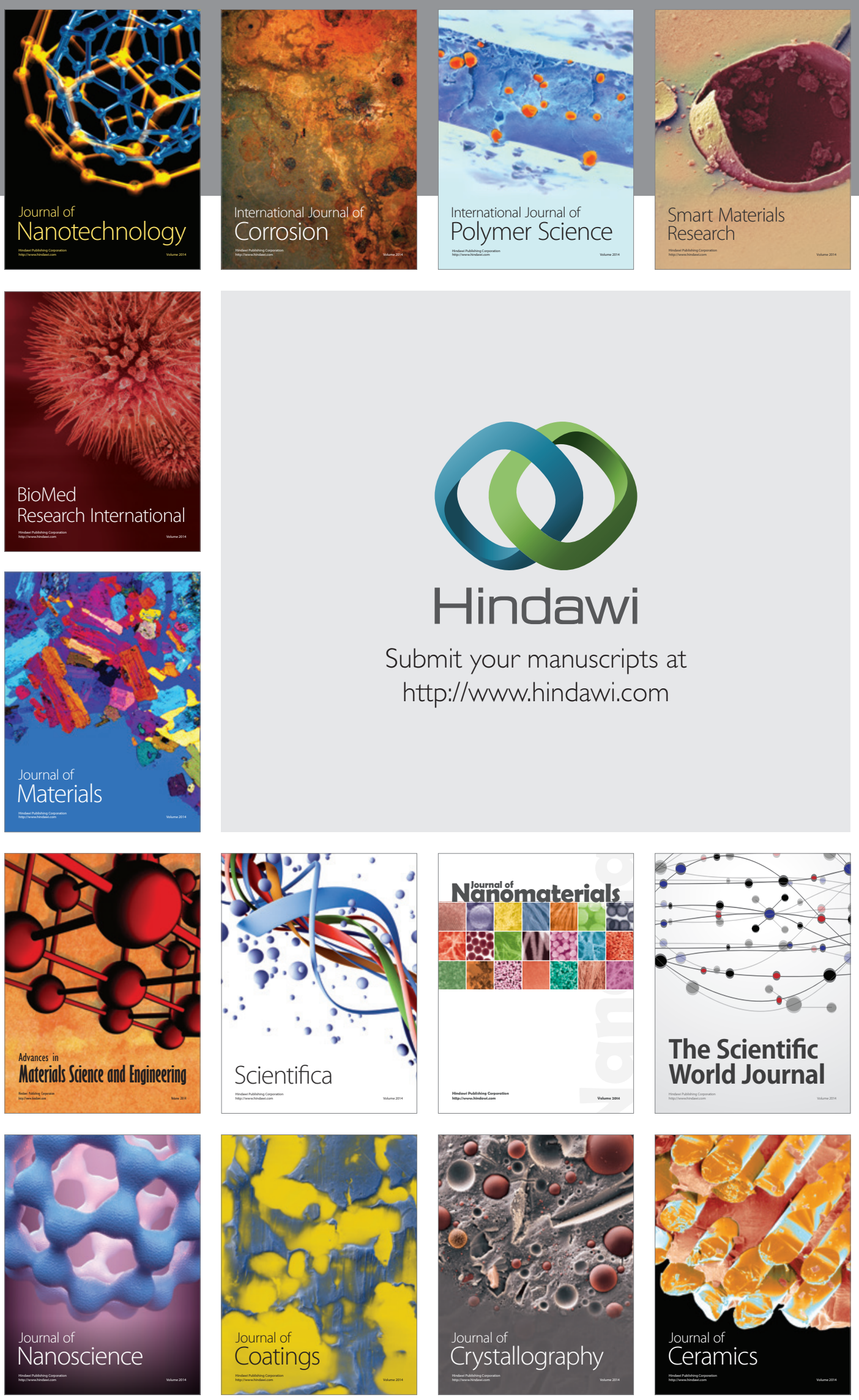

The Scientific World Journal

Submit your manuscripts at

http://www.hindawi.com

\section{World Journal}

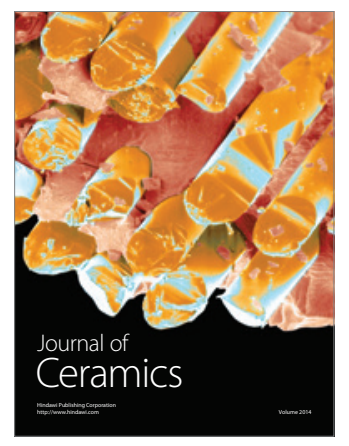

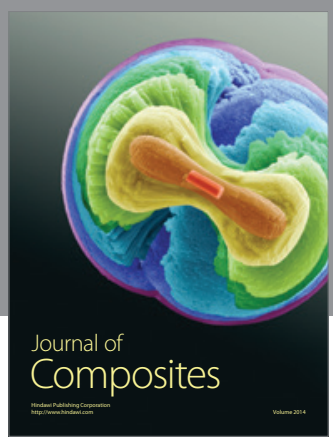
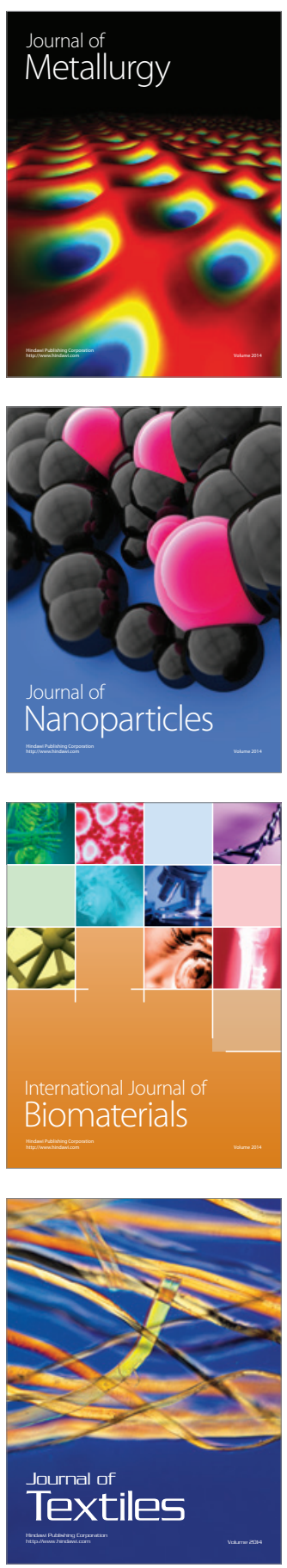